\title{
Carbamazepine, serum thyroid hormones and myocardial function in epileptic patients
}

\author{
Jouko I T Isojärvi, K E Juhani Airaksinen, Marja Repo, Arto J Pakarinen, Pasi Salmela, \\ Vilho V Myllylä
}

\begin{abstract}
Serum thyroid hormone and thyrotropin levels were assayed and the myocardial function was evaluated by measuring systolic time intervals both in 30 patients with epilepsy on long-term carbamazepine monotherapy and in 19 healthy volunteers. Serum thyroxine, free thyroxine and triiodothyronine levels were significantly lower $(p<0.001)$ in the patient group than in the control group and systolic time intervals were similar in both groups.
\end{abstract}

(F Neurol Neurosurg Psychiatry 1993;56:710-712)

Since the original report of Oppenheimer et $a l^{1}$ on the depression of serum protein bound iodine in epileptic patients treated with phenytoin, the changes in serum thyroid hormone levels during the use of antiepileptic drugs have been widely investigated.

Carbamazepine and phenytoin seem to have a similar effect on thyroid function: serum thyroxine (T4) and free thyroxine concentrations decrease, but serum thyrotropin (TSH) levels remain unchanged. ${ }^{2-4}$ However, serum triiodothyronine (T3) levels have not been found to be decreased as consistently as serum T4 and FT4 concentrations during carbamazepine medication. ${ }^{23}$ Serum T4 and/or FT4 levels decrease below the normal range after just two months therapy with carbamazepine in approximately $50 \%$ of patients, and remain at a similarly low level during long-term treatment. ${ }^{2}$ However, patients appear clinically euthyroid during carbamazepine medication.

Hypothyroidism leads to abnormalities in cardiac structure and function, and the severity of myocardial dysfunction seems to correlate with the grade of hypothyroidism. ${ }^{5}$ Measurement of systolic time interval (STI), a measure of myocardial function, ${ }^{6}$ shows a pattern characteristic of depressed myocardial contractility in hypothyroid patients. ${ }^{5}$

The present study aimed to evaluate whether patients with epilepsy receiving longterm carbamazepine medication reveal signs of myocardial dysfunction in STI correlating to hypothyroidism.

\section{Methods}

The study was approved by the ethical committee of the Medical Faculty of the University of Oulu. The principles of the Declaration of Helsinki were followed.

Thirty outpatients with idiopathic epilepsy participated in the study after giving their informed consent. The mean (SD) age of the patients was $23.6(3.4)$ years. There were 15 male patients [mean (SD) age $23.8(3.8)$ years], and 15 female patients [mean (SD) age $23.4(3.2)$ years]. All patients had carbamazepine monotherapy as their antiseizure medication and the therapeutic regime had been unaltered for at least one year before the study. The mean (SD) duration of carbamazepine medication of these patients was $4.9(2.9)$ years, the mean (SD) daily carbamazepine dose 509 (104) $\mathrm{mg}$, and the mean (SD) serum level of carbamazepine $24 \cdot 2(5 \cdot 0)$ $\mu \mathrm{mol} / \mathrm{L}$. The seizure control was in most cases good: 19 patients had had no seizures during the medication, four patients had less than one seizure per year, six patients had more than one seizure per year but less than one seizure per month, and one patient had more than one monthly seizure.

All patients were studied by the same person (MR) to evaluate the thyroid, cardiovascular and neurological status. Patients showing any symptoms or signs of illnesses other than epilepsy, and female patients who were pregnant, lactating, or receiving contraceptive pills, were excluded.

Nineteen healthy volunteers with a mean (SD) age of $25 \cdot 1(3 \cdot 3)$ years served as control subjects. There were 9 male [mean (SD) age $26.0(3.3)$ years] and 10 female control subjects [mean SD age 24.0 (3.0) years].

The blood samples of patients and controls were drawn and the STI performed in the morning at $8.00 \mathrm{am}$ after an overnight fast and before the morning dose of the medication was taken. All patients had been seizurefree for at least two weeks before entering the study.

Assays

Serum T4 and T3 concentrations were analysed by radioimmunoassay methods using reagent kits from Farmos Diagnostica (Turku, Finland). The sensitivity of the T4 
Table Serum hormone concentrations and STI of patients on long-term carbamazepine medication and of control subjects. Values are means (1 SD).

\begin{tabular}{lccl}
\hline & Patients $n=30$ & Control subjects $n=19$ & Statistics \\
\hline T4 (nmol/L) & $65 \cdot 9(13 \cdot 7)$ & $90 \cdot 6(18 \cdot 8)$ & $\mathrm{p}<0.001$ \\
FT4 (pmol/L) & $12 \cdot 5(2 \cdot 0)$ & $17 \cdot 0(2 \cdot 1)$ & $\mathrm{p}<0.001$ \\
T3 (nmol/L) & $1 \cdot 7(0 \cdot 2)$ & $2 \cdot 0(0 \cdot 3)$ & $\mathrm{p}<0.001$ \\
TSH $(\mathrm{mU} / \mathrm{L})$ & $2 \cdot 4(1 \cdot 3)$ & $1 \cdot 8(0 \cdot 7)$ & $\mathrm{NS}$ \\
PEP $(\mathrm{msec})$ & $104 \cdot 0(12 \cdot 8)$ & $108 \cdot 0(14 \cdot 7)$ & $\mathrm{NS}$ \\
LVET (msec) & $306 \cdot 5(22 \cdot 7)$ & $305 \cdot 6(18 \cdot 3)$ & $\mathrm{NS}$ \\
PEP/LVET & $0 \cdot 34(0 \cdot 04)$ & $0 \cdot 35(0.05)$ & $\mathrm{NS}$ \\
\hline
\end{tabular}

T4, thyroxine; FT4, free thyroxine; T3, triiodothyronine; TSH, thyrotropin; PEP, pre-ejection period; LVET, left ventricular ejection time.

assay was $5 \mathrm{nmol} / \mathrm{L}$, the coefficient of intraassay variation was $4.5 \%$, and that of interassay variation was $5 \cdot 7 \%$. The respective values for $\mathrm{T} 3$ assay were $0 \cdot 1 \mathrm{nmol} / \mathrm{L}, 5 \cdot 1 \%$, and $6 \cdot 2 \%$. Serum TSH concentrations were determined by a fluoroimmunometric method using reagent kits from Wallac Corp (Turku, Finland). The sensitivity of the assay was $0.03 \mathrm{mU} / \mathrm{L}$. The intra-assay variation was $5.4 \%$ and the interassay variation was $6.0 \%$. Serum FT4 concentrations were measured using radioimmunoassay kits obtained from Diagnostic Products Corp (Los Angeles, Ca, USA). The sensitivity was $0.13 \mathrm{pmol} / \mathrm{L}$, the intra-assay variability was $4.4 \%$, and the interassay variability $5 \%$. Serum carbamazepine concentrations were assayed by a fluorescence polarisation immunoassay system using an analyser (TDX, Abbott Diagnostic Division, Irving, Texas, USA). The sensitivity of the assay was $2 \cdot 1 \mu \mathrm{mol} / \mathrm{L}$, the intra-assay variation was $1.5 \%$, and the interassay variation was $2 \cdot 5 \%$.

\section{Measurement of STI}

STI were measured using Hewlett-Packard contact transducers $21050 \mathrm{~A}$ (Andover, $\mathrm{Ma}$ USA) and a multichannel ultraviolet recorder with $150 \mathrm{~mm} / \mathrm{sec}$ paper speed using a standard technique. ${ }^{8}$ Measurements were averaged over 10 consecutive cardiac cycles without knowledge of the subject's clinical data.

\section{Results}

The serum T4, FT4, and T3 concentrations were significantly lower ( $t$ test $p<0.001$ ) in the patient group than in the control group (table). No statistically significant differences were found in the serum TSH concentrations between these two groups. The STI (preejection period, PEP; left ventricular ejection time, LVET; PEP/LVET) were similar in the patient and the control groups.

All patients were clinically euthyroid. Six of the patients complained of fatigue and/or minor memory disturbances.

\section{Discussion}

Carbamazepine is a known inducer of the hepatic microsomal enzyme system, ${ }^{9}$ and as previously suggested, ${ }^{10}$ increased degradation of thyroid hormones in the liver is probably responsible for the decrease in serum thyroid hormone concentrations during $\mathrm{CBZ}$ medication.
But are the carbamazepine treated patients suffering from a sort of hypothyroid state or not? Subclinical hypothyroidism is nowadays a well known entity, characterised by relatively few clinical and biochemical abnormalities, and is defined solely by elevations in circulating TSH levels with serum thyroid hormone concentrations within the normal range. ${ }^{11}$ In patients on carbamazepine medication serum TSH levels do not increase, that is, the positive feedback mechanism due to low serum thyroid hormone concentrations is not activated and serum thyroid hormone levels remain low. Moreover, TRH stimulated secretion of $\mathrm{TSH}$ is not increased, either, during carbamazepine medication. ${ }^{2}$ It is possible therefore that either long-term carbamazepine therapy disturbs hypothalamic function or a new steady state of thyroid hormone balance develops during carbamazepine medication.

It has, however, previously been found to be very difficult to assess thyroid hormone effects at the tissue level in patients on antiepileptic drugs. Kodama et al, ${ }^{12}$ evaluated the basal metabolic rate (BMR) in epileptic children with low serum thyroid hormone levels treated with antiepileptic drugs. The patients were on polytherapy. BMR values were found to be low in some patients, but T4 replacement therapy had no improving effect on BMR values in most cases. Furthermore, Herman et al, ${ }^{13}$ evaluated BMR and thyroid function in carbamazepine treated patients with depression. Carbamazepine had no significant effect on BMR despite robust decreases in serum thyroid hormone concentrations.

It has been shown that thyroid hormones have a major role in the maintenance of normal left ventricular structure and function. ${ }^{14}$ Measurement of STI evaluates myocardial function. ${ }^{8}$ PEP prolongation, LVET shortening, and PEP/LVET increase is a pattern of STI which is characteristic of depressed myocardial contractility, and this pattern of STI has also been found in hypothyroid patients. ${ }^{5715}$

The STI of our patients with epilepsy receiving long-term carbamazepine medication did not differ from the STI of the control subjects, although the serum thyroid hormone concentrations were significantly lower in the patient group.

The decrease in serum thyroid hormone levels commonly seen in patients with epilepsy during carbamazepine medication is not severe enough to change the myocardial function of these patients.

This study was supported financially by grants from the Academy of Finland and the Epilepsy Research Foundation of Finland. We thank the personnel of the Department of Neurology and the Laboratory, and the Cardiovascular Division of the Department of Medicine of Oulu University Central Hospital for assistance in collecting samples, measuring STI and for laboratory work.

1 Oppenheimer JH, Fisher LV, Nelson KM, Jailer JW. Depression of the serum protein-bound iodine level by diphenylhydantoin. $\mathcal{f}$ Clin Endocrinol Metab 1961;21: 252-62. 
2 Isojärvi JIT, Pakarinen AJ, Myllylä VV. Thyroid function in epileptic patients treated with carbamazepine. Arch Neurol 1989;46:1175-78.

3 Isojärvi JIT, Pakarinen AJ, Ylipalosaari PJ, Myllylä VV. Serum hormones in male epileptic patients receiving anticonvulsant medication. Arch Neurol 1990;47: 670-76.

4 Liewendahl $\mathrm{K}$, Majuri $\mathrm{H}$, Helenius $\mathrm{T}$. Thyroid function tests in patients on long-term treatment with various anticonvulsant drugs. Clin Endocrinol 1978;8:185-91.

5 Bough EW, Crowley WF, Ridgway EC, Walker $H$ Maloof F, Myers GS, Daniels GH. Myocardial function in hypothyroidism. Relation to disease severity and response to treatment. Arch Intern Med 1978;138: 1476-80

6 Weissler AM, Harris WS, Schoenfeld CD. Systolic time intervals in heart failure in man. Circulation 1968;37: 149.

7 Crowley WF Jr., Ridgway EC, Bough EW, et al. Noninvasive evaluation of cardiac function in hypothyroidism. N Engl f Med 1977;296:1-6.

8 Weissler AM, Harris WS, Schoenfeld CD. Bedside techniques for the evaluation of ventricular function in man. Am F Cardiol 1969;23:577-83.

9 Perucca E, Hedges A, Makki KA, Ruprah M, Wilson JF, Richens A. A comparative study of the relative enzyme inducing properties of anticonvulsant drugs in epileptic patients. Br f Clin Pharmacol 1984;18:401-10.

10 Aanderud S, Myking OL, Strandjord RE. The influence of carbamazepine on thyroid hormones and thyroxine binding globulin in hypothyroid patients substituted with thyroxine. Clin Endocrinol 1981;15:247-52.

11 Evered DC, Ormston BJ, Smith PA, Hall R, Bird T. Grades of hypothyroidism. BMF 1973;1:657-62.

12 Kodama S, Tanaka $\mathrm{K}$, Konishi $\mathrm{H}$, et al. Supplementary thyroxine therapy in patients with hypothyroidism induced by long-term anticonvulsant therapy. Acta induced by long-term anticor

13 Herman R, Obarzanek E, Mikalauskas KM, Post RM, Jimerson DC. The effects of carbamazepine on resting metabolic rate and thyroid function in depressed patients. Biol Psychiatry 1991;29:779-88.

14 Steinberg AD. Myxedema and coronary artery disease: a comparative autopsy study. Ann Intern Med 1968;68: 338-44.

15 Hillis WS, Bremner WF, Lawrie TDV, et al. Systolic time intervals in thyroid disease. Clin Endocrinol 1975;4: 617-24.

16 Cooper DS, Halpern R, Wood LC, Levin AA, Ridgway EC. L-thyroxine therapy in subclinical hypothyroidism. A double-blind, placebo-controlled trial. Annals Intern Med 1984;101:18-24. 